\title{
Masculinidades no hegemónicas en el Chile neoliberal. Reflexiones sobre intervención social*
}

\author{
Non-hegemonic masculinities in neoliberal Chile. \\ Reflections on social intervention
}

Masculinidades não hegemônicas no Chile neoliberal. Reflexões sobre a intervenção social

Rodrigo Azócar González**

\begin{abstract}
RESUMEN
El presente artículo busca profundizar la reflexión entre la intervención social y las características de las masculinidades no hegemónicas que resurgen en el contexto del neoliberalismo postdictadura. La caracterización compleja de estas masculinidades se muestra como una necesidad urgente para acercar la intervención social a las subjetividades abyectas que se desarrollan en contextos de profundas desigualdades sociales, característica que se evidencia en América Latina, y especialmente en Chile, con el surgimiento de dictaduras cívico-militares en la segunda mitad del siglo XX y con la transformación de la sociedad por la implantación del modelo neoliberal como proyecto homogeneizador que instala al individuo por sobre la comunidad, atomizando al sujeto de intervención. Las masculinidades no hegemónicas, en este contexto, se pueden entender como resultado de la relación entre sociedad e individuo marginal y/o marginado en función de su orientación sexual, requiriendo su caracterización que privilegie miradas desde la complejidad.
\end{abstract} Palabras clave: masculinidades, intervención social, neoliberalismo, diversidad sexual.

\footnotetext{
* El presente artículo informa de los resultados preliminares de la investigación doctoral "Masculinidades no hegemónicas en el Chile post-dictadura", presentada al programa de Doctorado en Estudios Interdisciplinares de Género de la Universidad de Huelva, España.

** Chileno. Magíster en Antropología Social, académico Universidad Autónoma de Chile. E-mail: rodrigo.azocar@uautonoma.cl
} 


\begin{abstract}
The present article seeks to deepen the reflection between social intervention and the characteristics of non-hegemonic masculinities that resurface in the context of post-dictatorship neoliberalism. These masculinities' complex characterization shows an urgent need to bring social intervention closer to the abject subjectivities that develop in contexts of profound social inequalities, characteristic of Latin America, and especially in Chile. The emergence of civic-military dictatorships in the second half of the 20th century and society's transformation by a neoliberal model as a homogenizing project installs the individual over the community, atomizing the intervention subject. Non-hegemonic masculinities, in this context, can be understood as the result of the relationship between society and the marginal and/or marginalized individual based on his sexual orientation, requiring a characterization that privileges views from the perspective of complexity.
\end{abstract}

\section{RESUMO}

Este artigo busca aprofundar a reflexão entre a intervenção social e as características das masculinidades não hegemônicas que emergem no contexto do neoliberalismo pós-ditadura. A caracterização complexa destas masculinidades se apresenta como uma necessidade urgente de aproximar a intervenção social das subjetividades abjetas que se desenvolvem em contextos de profundas desigualdades sociais, característica que se evidencia na América Latina, e especialmente no Chile, com o surgimento de ditaduras cívico-militares na segunda metade do século XX e com a transformação da sociedade pela implementação do modelo neoliberal como um projeto homogeneizador que instala o indivíduo acima da comunidade, atomizando o sujeito da intervenção. As masculinidades não hegemônicas, neste contexto, podem ser entendidas como o resultado da relação entre a sociedade e o indivíduo marginal e/ou marginalizado em função de sua orientação sexual, exigindo sua caracterização que privilegia visões desde a perspectiva da complexidade.
Key words: masculinities, social intervention, neoliberalism, sexual diversity.

Palavras-chave: masculinidades, intervenção social, neoliberalismo, diversidade sexual. 


\section{A modo de contexto}

La construcción social de las masculinidades (Muñoz, 2017) en un contexto neoliberal ha permitido observar la configuración de las subjetividades desde la mirada crítica de las ciencias sociales, en relación con los procesos sociales, políticos y económicos posteriores a la caída del comumismo en Europa oriental, la instalación de dictaduras cívico-militares en América Latina y la consolidación del pensamiento neoliberal como único modelo posible, en un contexto donde el paso de la tensión bipolar del poder de la guerra fría se transformó en un modelo único y homogenizador de escala mundial. Este contexto de profundas transformaciones se observa claramente en Chile con el golpe de Estado que derroca al gobierno de la Unidad Popular, en 1973, y la instalación de una dictadura que pavimentó el camino hacia la transformación profunda de la sociedad local, mediante el terror y la violación sistemática de los derechos humanos, escenario propicio para desarrollar en el país un proceso de reconfiguración de todos los aspectos de la vida social hacia un modelo capitalista, que sentaría las bases de una sociedad neoliberal. La dictadura se vincula con las transformaciones del capitalismo en el mundo, a través de la influencia que ejercen los gobiernos de Estados Unidos e Inglaterra y la incorporación, desde 1975, de grandes cambios impulsados por los Chicago Boys en la llamada "vía chilena al capitalismo". En palabras de Tomás Moulián:

Estos dieciséis años de dictadura significan un programa estable y consistente que tiene éxito en la realización de sus premisas: genera un desarrollo sumamente desigual, pero permite un crecimiento económico relativamente estable y de larga duración, cosa que en Chile no había sucedido por la inestabilidad de los programas que se llevaban a cabo y la muy fuerte influencia de los programas antiinflacionarios que estaban obligados a llevar adelante los gobiernos de esa democracia. (Carrillo, 2010, p. 146)

Este proceso político, social y económico propició la transformación neoliberal que ha permeado todos los espacios de interacción con los sujetos, incluyendo el propio proceso de construcción de uno mismo, es decir, la creación de las subjetividades que dan identidad y características a las personas en un contexto social. Desde el control dictatorial del sujeto (Iglesias, 2015), emergen las nuevas subjetivida- 
des que entregan formas y espacios de participación e influencia, reorganizadas a través de modelos que establecen una forma de relación social basada en los principios jurídico-políticos que impone la dictadura desde sus bases ideológicas neoliberales, estableciendo un campo hegemónico de dominación desde los apectos culturales y valóricos promovidos por el nuevo régimen.

El surgimiento de este sujeto neoliberal en un contexto de profundización de las diferencias y desigualdades, característica muy relevante del modelo en su implementación en América Latina y especialmente en Chile, posibilita la atomización de las demandas sociales y la reorganización a través de colectivos que reclaman inserción e inclusión en un sistema profundamente excluyente. La construcción de los vínculos comunitarios y políticos se ve condicionada a los espacios de participación que establece y permite el neoliberalismo, especialmente cuando esos colectivos excluídos están relacionados con aquellas cuestiones críticas que afectan la hegemonía, homogenización y conservadurismo de la sociedad neoliberal. Es decir, la visibilización de otras formas de organización de la vida cotidiana, que no responden a las estructuras promovidas por la razón oficial.

En el campo del género, la relación que establece el patriarcado con el neoliberalismo (Miguel, 2015) posibilita la profundización de las desigualdades basadas en un permanente sexismo en todos los ámbitos de la vida social, la invisibilización de las diversidades sexuales y desvalorización de sus demandas por inclusión y respeto, junto a la aún creciente violencia hacia las mujeres y los crímenes por razones de orientación sexual. Específicamente desde la construcción social de las masculinidades, la reproducción de una versión única o hegemónica profundiza aquella relación con el patriarcado que perpetúa las diferencias y promueve las desigualdades que, para las diversidades sexuales, ha significado el sometimiento a los valores y normas del sistema, en vinculación con otras dimensiones sociales como la raza y clase social (Pelucio, 2011), delimitando aún más su campo de acción, injerencia y visibilidad, y poniendo a los sujetos que no se identifican con aquellas masculinidades hegemónicas en una situación de potencial vulnerabilidad. En efecto, la relación de las masculinidades con su contexto sociocultural es fundamental para la comprensión de la versión dominante de lo masculino, como de las disidencias. Para R.W. Connell: 
La historia mundial y la globalización contemporánea deben ser parte de nuestra forma de comprender las masculinidades, en la medida en que las vidas individuales reciben fuertes influencias de las luchas geopolíticas, del imperialismo y colonialismo, de los mercados globales, de las corporaciones multinacionales, la migración laboral y de los medios transnacionales de comunicación. (2006, p. 187)

Desde aquella reflexión sobre la construcción social de las masculinidades no hegemónicas, este artículo procura profundizar en estos elementos que los propios sujetos identifican y vinculan entre sus biografías y los contextos del neoliberalismo, los mismos que posibilitan la identificación con una sexualidad abyecta, comprendiendo la construcción desde los márgenes cuando aquella identidad masculina no pertenece a los moldes hegemónicos impuestos por el patriarcado (Marqués, 1997). Desde allí la relevancia de la intervención social (Azócar, 2015), que se transforma en una relación emancipadora (Martínez y Agüero, 2018) que entrega posibilidades de visibilización y transformación de los contextos de vulnerabilidad propios de un modelo patriarcal neoliberal. Esta relación se organiza en el análisis y reflexiones que surgen de las entrevistas semiestructuradas realizadas a trece sujetos que se identifican con una masculinidad no hegemónica, en el marco de la investigación doctoral denominada "masculinidades no hegemónicas en el Chile posdictadura", del programa de Doctorado en Estudios Interdisciplinares de Género de la Universidad de Huelva.

\section{Algunas apreciaciones sobre las masculinidades no hegemónicas}

La construcción de las masculinidades hegemónicas tiene una clara base en las violencias que se ejercen hacia las mujeres y otredades feminizadas. En este sentido, "las masculinidades son una posición, que no es fija sino condicionada por otras categorías de distinción social y que trasciende los cuerpos biológicos y las individualidades, pero que es referida a un colectivo: el de los hombres" (Careaga Pérez y Cruz, 2006, p. 10). Esta versión de lo masculino está en relación con un opuesto desacreditado socialmente, que genera espacios de vinculación desde la superioridad masculina promoviendo las relaciones de dominación en los contextos sociales complejos y condiciones de 
vulnerabilidad. La dimensión de la vulnerabilidad es un pilar desde donde se construye la posterior dominación. En este contexto se van profundizando las diferencias para constituirse en desigualdades que afectan a las identidades disidentes en relación con el modelo de masculinidad dominante en la sociedad, por lo tanto, de aquella versión aceptada y validada.

Esta forma, la masculinidad tradicional, llamada más exactamente masculinidad hegemónica, no es solo una manifestación predominante, sino que como tal queda definida como modelo social hegemónico que impone un modo particular de configuración de la subietividad, la corporalidad, la posición existencial del común de los hombres y de los hombres comunes, e inhibe y anula la jerarquización social de las otras masculinidades, más aún en estos tiempos de globalización homogeneizante donde esta masculinidad hegemónica también lo es. (Bonino, 2002, pp. 8-9)

En referencia a las vinculaciones entre las masculinidades y los contextos de hegemonía, es que los mandatos de la masculinidad (Segato, 2010) que existen para los hombres les obliga a mostrar y comprobar su virilidad mediante prácticas y rituales, lo que implica una directa oposición con los valores asociados a lo femenino. La demostración de la masculinidad, en todo momento, es un mandato implícito que cada hombre que quiera ser reconocido y valorado como tal debe cumplir, exponer, divulgar, pero especialmente demostrar. Este concepto ayuda a acercar la idea de la masculinidad hegemónica, en constante cambio y transformación, hacia las realidades latinoamericanas desde donde se vinculan con otros factores que le otorgan mayor complejidad. Es decir, están en relación con los contextos sociales, políticos, económicos y culturales que son especialmente determinantes en la configuración de las sociedades en esta parte del mundo. Comprender las características de las masculinidades hegemónicas requiere un análisis detallado y profundo del contexto en el que se desarrollan. Por ello, considero importante señalar que en este trabajo, al referirme a masculinidades no hegemónicas o contrahegemónicas, lo hago desde la comprensión de estas subjetividades en el contexto de América Latina.

Para Bonino (2002), las masculinidades hegemónicas están sustentadas en cuatro ideologías: el patriarcado, el individualismo de la modernidad, la exclusión y subordinación de la otredad y el heterosexis- 
mo homofóbico (p. 13). Estos valores otorgan un objetivo e identidad a esta versión única de ser hombre, posibilitando la rápida identificación de aquellos contextos y sujetos que se alejan de estos patrones, permitiendo su sometimiento y dominación. Es por ello que este artículo identifica a las masculinidades no hegemónicas o contrahegemónicas como aquellas subjetividades que construyen una idea de lo masculino fuera de estos patrones valóricos, y que van a generar un espacio de disputa directa con la versión única de sí mismo. En estas masculinidades no hegemónicas caben los sujetos que se identifican con aquellas diversidades sexuales que logran reconocer su rol y función en el sistema patriarcal, consideradas en el presente trabajo.

Para analizar las identidades masculinas en nuestra sociedad latinoamericana, es obligatorio incorporar los elementos que componen las relaciones y administración del poder. La deconstrucción de aquella masculinidad hegemónica nos puede acercar a lo que históricamente han promovido los diversos movimientos feministas, es decir, la comprensión de la situación de la mujer y las otredades feminizadas en nuestras culturas, la organización social de las diversidades sexuales, las libertades personales, el cuerpo y el placer, entre otros tantos temas. Por ello, es necesario acercarse a la configuración del machismo en la organización de nuestra sociedad, la instrínseca relación entre patriarcado y masculinidad(es) y cómo estas condiciones nos afectan a todos y todas en nuestra vida cotidiana.

La construcción y socialización de la masculinidad dominante se basa en aspectos históricos, relacionados con los contextos culturales desde donde se han formado y organizado las estructuras de relaciones entre las personas. Corresponde a una forma única y promovida por las instituciones de la manera válida (y socialmente validada) de ser hombre. Esta versión homogenizadora se basa en la exhibición de todo tipo de fuerza y control (económico, social, cultural, sexual, entre otros), que se deben certificar y demostrar en todo momento y lugar, con el fin de obtener la aprobación de los otros, quienes tienen el poder de determinar si aquellas manifestaciones de esta masculinidad hegemónica están dentro de lo que la sociedad aprueba como masculino. Cualquier tipo de vinculación con otro tipo de subjetividad alejada del patrón hegemónico, implica el retiro de esta certificación de masculinidad y la ubicación dentro de una categoría de me- 
nor valor que posibilita y autoriza al varón dominante al ejercicio del poder absoluto por sobre ese sujeto disidente. Esta normalización o construcción de un varón verdadero y validado, implica la performatividad permanente desde el contexto de la hegemonía y la mantención de los privilegios de la casta masculina, que no solamente es ejercida por hombres que cumplen con los requisitos establecidos. Esta masculinidad es dominante, pues está siendo constantemente reproducida y promovida por una mayoría, a través de todos los canales de comunicación y socialización, lo que afecta no solo a los hombres, sino a todas y todos. Esta certificación constante de la calidad de hombre es también una exigencia social permanentemente demandada. Las instituciones y los sujetos necesitan de estas demostraciones de masculinidad, con el fin de organizar y ubicar al sujeto dentro de categorías que permitan identificarlo rápida y claramente con un patrón cultural establecido.

Las características que deben cumplir los individuos para poder ser llamados "hombres" se organizan en torno a los patrones establecidos desde el machismo, pero asumen matices diferentes desde los propios contextos culturales desde donde son exigidos. Los mandatos de la masculinidad hegemónica están en la línea del proveer y sostener, es decir, de ser capaz de administrar la vida de otros y para otros. Estas características, que están en directa relación con el modelo político, social y económico que nos rige, valoran al hombre por su condición de responsable de entregar todo aquello que sea necesario, desde la perspectiva de los productos para la manutención de otre. Estas características son solamente válidas cuando el sujeto es heterosexual, puesto que aquella orientación sexual asegura la perpetuación del modelo de dominación masculina mediante la validación y promoción de instituciones, prácticas, relaciones y mandatos que ubican a los seres humanos desde una organización social masculinizada y masculinizante.

Sobrevivir a la masculinidad hegemónica, en el contexto del patriarcado, ha sido una tarea no solo para quienes conscientemente disienten de esta organización social, sino también para los propios varones heterosexuales, que comprenden la violencia de los patrones culturales impuestos que presionan a la constante certificación y demostración de masculinidad y dominación. 
La sexualidad, por tanto, se transforma en uno de los mandatos elementales de esta masculinidad hegemónica, en la que la permanente reafirmación de heterosexualidad como modelo único y válido, en todos los ámbitos de la vida social, margina a quien no se acerque o demuestre practicar y adherir a estas normas. En este contexto de heterosexualidad obligatoria, el patriarcado castiga y pone en tensión toda manifestación de disidencia de este dogma, promoviendo la sanción social y degradación permanente de mujeres y disidentes sexuales, como manifestación necesaria de reafirmación de la dominación masculina promovida socialmente.

La dominación y la violencia hacia otre, elemento central de esta masculinidad hegemónica como una medida universal, se manifiesta en la opresión hacia mujeres, hacia la diversidad sexual y hacia toda diferencia que marque distancia con las manifestaciones de esta versión hegemónica de lo masculino. En esta obligatoriedad de demostración de lo masculino, la dominación y sometimiento se transforma en el verificador necesario para aprobar la certificación masculina. Esta constante prueba de masculinidad posibilita la sobrevivencia a los códigos culturales de la dominación, entrega la posibilidad de ser parte de una red de relaciones validadas desde el patriarcado y asegura al sujeto un grupo de oportunidades que son negadas a las mujeres y a las disidencias.

El aprendizaje de género [...] es adulto y heterosexual. Responde a un sujeto que se ubica en una posición de poderal interior de las relaciones sociales generacionales y de género. No es cualquier ubicación la que hay que replicar en el proceso de hacerse varón, es aquella que garantiza unas ciertas posibilidades de acceso a los bienes materiales y simbólicos que otorgan los privilegios masculinos. (Duarte y Farías, 2019, pp. 119-120)

Rita Segato (2016) incorpora la idea de "masculinidades opacas" para referirse a aquellos actos que producen los hombres, condicionados por los mandatos de masculinidad, y que no tienen una reflexión o racionalidad descriptible, sino que los generan desde una condición de inercia. No son parte ni se ven involucrados en estas acciones, es decir, están desprovistos de sentido y compromiso, pues son, simplemente, acciones de demostración performáticas desde la necesidad de validación y no desde la vinculación que producen sus actos. Desde 
esta definición, las masculinidades no hegemónicas, es decir, aquellas masculinidades que no están dentro de la órbita de lo socialmente validado y que se vinculan desde los márgenes establecidos por el patriarcado, están obligadas a la reflexividad, es decir, a pensar la propia práctica como ejercicio de cuestionamiento constante de los problemas que genera el patriarcado como sistema de organización social. La identificación de los sujetos desde las masculinidades no hegemónicas obliga a ubicarse como parte del problema y, por tanto, a entenderse como sujetos en constante interacción con la dominación y violencia que genera la sociedad patriarcal, pero desde las posibilidades que entregan los márgenes de aquella sociedad.

La construcción de sociedades diversas, justas, inclusivas e igualitarias requiere de la concurrencia de las categorías que los feminismos han construido desde la histórica labor de denuncia y visibilización de las diferencias e inequidades. Comprender, por tanto, las masculinidades abyectas, implica reconocer la utilización de este adjetivo para marcar aquella disidencia de lo hegemónico y la oposición directa al orden heterosexual como sistema universalmente válido. Por el hecho de identificarse como tal y visibilizar esta disidencia, se los obliga a una relación con el contexto en que se desenvuelven desde la tensión constante de reconocerse como marginados, o incluso desde la idea de outsiders (Becker, 2009) como su lugar en un mundo organizado para quienes siguen la norma impuesta, especialmente desde la concepción que se tiene del cuerpo masculino hegemónico. El cuerpo material no cambia, son las relaciones que establecemos con el cuerpo las que cambian, los valores y funciones que le entregamos en función del contexto social, político y económico en que nos encontramos.

Para Connell:

La opresión coloca las masculinidades homosexuales en el fondo de una jerarquía de género entre los hombres. Para la ideología patriarcal, la homosexualidad desecha simbólicamente, incluyendo desde un gusto quisquilloso al decorar la casa hasta el placer anal receptivo. Por lo tanto, desde el punto de vista de la masculinidad hegemónica, la homosexualidad se asimila con facilidad a la feminidad. De ahí la ferocidad de los ataques homofóbicos, desde el punto de vista de algunas teorizaciones sobre lo gay. (2015, p. 114) 
Por ello, las masculinidades no hegemónicas o contrahegemónicas que relacionarían al sujeto homosexual, se vinculan desde los contratos de género que tensionan la relación con los cuerpos, sus usos y funciones, dentro de un contexto determinado. Los significados que van produciendo con el transcurso de la historia, se ven vinculados a las subjetividades características de las sociedades en las que se desarrollan. Aquellas masculinidades, según Connell, están organizadas en tres esferas que dan luces sobre su función en la sociedad patriarcal:

[las esferas] productiva, poder y cathesis. Es decir, en primer lugar una división sexual del trabajo configurada en torno a la estratificación del trabajo productivo según las relaciones de género; en segundo lugar, el poder que ha configurado la dominación de los hombres sobre las mujeres con el patriarcado histórico, y, en último lugar, la cathesis, que se refiere a la emocionalidad, la construcción social del deseo. (Martín \& de Lima, 2020, p. 6)

La vida cotidiana se organiza en los escenarios reproductivos y productivos, en los que estos cuerpos cumplen una función particular y un rol específico dentro de la estructura patriarcal. Por tanto, las relaciones entre sujetos van formando relaciones y jerarquías, dominación, subordinación, ejercicio del poder. Estos elementos y acciones no son espontáneos, sino que responden a una planificación intencionada, con un fin y un propósito claro, directamente relacionado con lo que se espera de esos sujetos en el contexto social. Desde aquí se va estableciendo una relación directa entre estos cuerpos masculinos no hegemónicos y marginalizados con el orden social neoliberal, que organiza a los sujetos desde su función productiva y entrega especial valor a la hegemonía como estrategia aglutinadora y organizadora de la sociedad en función de la producción y acumulación de riqueza.

Es en estos contextos complejos desde donde surge el objetivo de esta investigación, profundizar en la relación observada entre las masculinidades no hegemónicas y el Chile posdictadura, especialmente desde los contextos que produce y reproduce el capitalismo neoliberal. Estas subjetividades, que se reconocen desde la diferencia al prescindir (o no) del mandato heterosexual, ubican al sujeto en una cartografía que le obliga a exteriorizar que tan cerca o lejos vivirá esa condición abyecta dentro del contexto neoliberal y, por tanto, a visibilizar aquella contradicción que surge del reconocerse diferente del modelo social 
patriarcal y heterosexual dominante. En aquella relación, la intervención social se transforma en catalizadora de las diferencias e inequidades, obligándole a describir y definir estas subjetividades desde el contexto sociocultural en el que se encuentra.

\section{Masculinidades no hegemónicas en el contexto neoliberal chileno}

En la actualidad, el mercado toma un rol protagónico en la configuración de las sexualidades. El avance y profundización del capitalismo y la instalación del sistema neoliberal, posicionan al contexto mercantil como un espacio de interacción y sustento fundamental para analizar las posibilidades de cambio social, vinculaciones con el Estado y relaciones sociales. En materia de derechos, existe mayor conciencia del valor de las diversidades, pero esto no lleva necesariamente a la construcción de sociedades inclusivas y diversas (Barrientos y Espinoza, 2019). Con estas relaciones entre mercado y transformaciones sociales, producto de las desigualdades que instala el sistema, las sexualidades se convierten en un tema de debate desde lo económico, quitándole su valor político y reivindicatorio, situación que impide el choque, reflexión y transformación con los contextos de desigualdad e inequidad que producen. Las masculinidades no hegemónicas (o contrahegemónicas), por tanto, pierden la oportunidad de visibilizar sus condiciones de exclusión y subordinación a un orden patriarcal.

Las condiciones que se presentan desde un capitalismo heteropatriarcal constituyen un contexto de vinculación y organización político, económico y social, que afecta primordialmente a la vida cotidiana de mujeres y disidencias. Para este tipo de capitalismo, la producción y el mercado son el centro de las relaciones que se establecen entre sujetos e instituciones, y, por tanto, las relaciones de consumo son las que determinarán y condicionarán aquellas relaciones.

En ese sentido, pensando la economía desde una perspectiva feminista, esta misma tiene un carácter primordialmente social, pues atiende a todos los conflictos generados desde las relaciones de poder, dominación e inequidad, desde un eje centrado en la interacción política de sus involucrados. Existe, por tanto, una tensión con las ideas que promueve la teoría económica neoclásica, que es la base del neoliberalismo. Ese modelo de sistema-mundo económico, polí- 
tico, social y cultural rige todos los quehaceres de la vida cotidiana, genera la posibilidad de valoración de ciertos trabajos versus la desvaloración de otros (trabajo productivo versus trabajo reproductivo), promoviendo las inequidades. Desde ese eje, la economía feminista busca visibilizar el trabajo asociado a lo femenino, ya que la economía neoclásica ha privilegiado mostrar al sujeto trabajador masculinizado y solo desde la perspectiva de la relación productiva. Por tanto, hace sentido pensar que el neoliberalismo es "un término usado para referirse al cambio generalizado desde una época de social democracia y liberalismo progresista hacia políticas e instituciones más preocupadas de promover el mecanismo de mercado y que son más amistosas con los negocios y el capital" (Rodriguez, 2019, p. 13), despojando al sujeto de un vínculo y sentido con su contexto, valorando el individualismo por sobre él, estableciendo de una responsable interacción con la comunidad. Esto se refleja en todos los ámbitos de la vida cotidiana, profundizando las inequidades que genera. Para Rita Segato, estas condiciones son especialmente observables en la trayectoria histórica de dos países:

Chile y Qatar proporcionan los dos modelos que exponen las tendencias de la presente fase apocalíptica del proyecto histórico del capital. Chile, con la aplicación ortodoxa de la receta de Milton Friedman, que conduce a un régimen societario regido por el mercado. La tristeza que impregna la sociedad chilena es frecuentemente asociada por la propia gente al efecto de precariedad que ese modelo le imprime a la vida, en un sentido del término precariedad que lo desvincula de la idea de pobreza o carencia, para significar con precisición precariedad de la vida vincular, destrucción de la solidez y estabilidad de las relaciones que arraigan, localizan y sedimentan afectos y cotidianos. La experiencia de interperie y desprotección se apodera así de una nación. (2016, p. 100)

La construcción de las masculinidades no hegemónicas en los contextos del neoliberalismo, se produce a razón de las crecientes desigualdades (Palet, Aguirre y PNUD Chile, 2017), en las que el poder es ejercido casi en su totalidad por hombres, tornándose relevante la relación entre estas masculinidades y las desigualdades de clase para comprender la profundidad y magnitud de las desigualdades en el Chile neoliberal. 
Este modelo de relaciones y valoraciones de las subjetividades, promovido por el neoliberalismo, ubica a las masculinidades contrahegemónicas en una posición de subalternidad que dificulta y hace aún más compleja la posibilidad de análisis e intervención en el contexto de la superación de aquellas diferencias, especialmente al comprender los aspectos transversales que la configuran. Estos marcadores sociales de diferencia (Pelucio, 2011) están en estrecha relación con el contexto social y cultural en que se producen, característico de los contextos latinoamericanos.

Es por ello que:

Pensar la masculinidad como una posición social permite comprender la articulación entre género y otros ejes de desigualdad social como la clase la etnia o edad e identificar los intereses compartidos de los hombres con base en la posición que ocupan y también las contradicciones entre distintos grupos de hombres. (Guevara, 2008, p. 89)

Es en esa relación de las masculinidades y posición social que la incidencia del contexto neoliberal, especialmente desde sus condiciones en Chile, complejizan la posición de las disidencias sexuales, especialmente por la infravaloración que se tiene de sus condiciones de precariedad, muchas veces disfrazadas por el acceso al consumo, la participación que tienen algunos sujetos subalternos en los medios de producción, la formación profesional a la que pueden acceder y las posibilidades de endeudamiento, todo lo cual entrega una sensación de realización y participación en la vida social, pero que solo se limita a los espacios de consumo promovidos por el neoliberalismo. Es decir, una ciudadanía reflexiva y diversa se vuelve aún más compleja desde el espejismo neoliberal. Por ello, si bien ya no se comprende al sujeto homosexual desde la sanción moral y la perversidad, la transformación tampoco le han otorgado calidad de sujeto pleno:

Observamos que la categoría de perverso/perversión ha desaparecido, aunque hay muchos que se preguntan si asistimos, finalmente, a una suerte de domesticación de la homosexualidad y si hay realmente una incorporación potencialmente transgresora y transformadora de este eros en los rituales de la cultura heteronormativa. (Barrientos y Espinoza, 2019, p. 299) 
Por consiguiente, pensar las masculinidades no hegemónicas dentro del contexto neoliberal actual, implica el reconocimiento de la condición de subalternidad del sujeto, especialmente desde los espacios de vulnerabilidad que le otorgan una posición social desvalorada desde la heteronorma imperante, constituyéndose en un factor de exclusión relevante y permanente, especialmente promovido por los contextos sociales, económicos y políticos, en constante conflicto en nuestra América Latina.

Con lo anterior, los discursos biográficos de sujetos que se identifiquen con estra contrahegemonía y sus aproximaciones a los contextos neoliberales que impactan en sus historias, serán de gran relevancia para promover contextos de intervención social situador y coherentes con su contexto, pero que, además, promuevan el empoderamiento y emancipación del sujeto excluido

\section{Aspectos metodológicos}

El presente artículo aborda y profundiza en algunos elementos contenidos en la investigación doctoral "Masculinidades no hegemónicas en el Chile posdictadura", del programa de Doctorado en Estudios Interdisciplinares de Género de la Universidad de Huelva. Desde ese contexto, se planteó organizar este artículo como una invetigación desde un enfoque cualitativo (Hernández y Mendoza, 2018), dada la posibilidad de vincularse con los significados que los sujetos otorgan a sus experencias desde sus propios relatos. Para ello, se propuso como objetivo establecer relaciones entre la experiencia de identificación con una sexualidad contrahegemónica y los contextos neoliberales locales. Dado el interés por acercarse a los discursos en relación con los procesos personales que conlleva la construcción de su identidad y la valoración de la interacción con el contexto social, político, cultural y económico en que se encuentra inserto el sujeto, la técnica de producción de información utilizada fue la entrevista semiestructurada (Yuni y Urbano, 2014, p. 84), valorando la posibilidad de flexibilidad que entrega en la recogida de datos y vinculación con los sujetos de investigación.

En cuanto al muestreo, este correspondió a intencional de tipo opinático (Ruiz Olabuénaga, 2012, p. 64), pues la selección de entrevistados se organizó en función de las posibilidades de acceder a discursos 
diversos y atingentes a la temática de la investigación. Desde esa premisa, se seleccionaron trece sujetos varones chilenos, nacidos desde 1990 (correspondiente al fin de la dictadura cívico-militar en Chile), residentes en los tres principales polos urbanos del país (Santiago, Valparaíso y Concepción) y que se identifican con una sexualidad contrahegemónica, es decir, reconocen la influencia de la heteronorma en la construcción de su identidad diversa.

Respecto del análisis, este artículo se acerca a la propuesta que hace el Análisis Crítico del Discurso (Pardo Abril, 2007) en relación con el compromiso social y político en el cuestionamiento y organización de una sociedad diferente, desde la profundización de las configuraciones discursivas centradas en los procesos históricos de dominación y subordinación que sustentan nuestra sociedad actual. En ese sentido, el Análisis Crítico del Discurso:

Surge como heredero del estudio del lenguaje en tanto práctica social en un contexto particular y con un interés preponderante en la relación de dominación y poder, para lo cual reconoce el discurso público como la expresión donde se pone de relieve la relación entre lucha por el poder y conflicto de intereses. $(2007$, p. 60)

El análisis se estructuró sobre la base de tres categorías emergentes: identificación, mandato de masculinidad y contexto neoliberal, las que permiten organizar y vincular los discursos recogidos con la propuesta teórica precedente.

\section{Resultados y discusión}

\section{Categoría identificación}

Esta categoría surge por la evidencia de los relatos que establecen un punto de profundización y vinculación de la biografía personal con elementos que componen el sistema neoliberal en el Chile actual. La relación entre la construcción identitaria y el contexto político, social y económico permite identificar aspectos de la vida social que van a repercutir en las subjetividades.

Entonces yo siempre fui súper libre, súper fluido en cuanto, como, a la identidades binarias de género, nunca me sentí representado por ninguna de las dos, sin embargo, no me molesta que esté biolo- 
gicamente en cuerpo de hombre, tampoco me interesa intervernirlo, ni nada por el estilo, si no que, para mí, es imposible reconocerme como hombre bajo todas las características, bajo todos los imaginarios, bajo toda la... lo sujeto político que significa ser "hombre" poh, cachai? Entonces, es súper, súper complicado para mí considerarme hombre, por eso creo que no lo soy y, como te contaba, desde chico que tampoco nunca me sentí como alineado bajo estas normas de género binario. (E12, 23 años, Concepción)

En el relato precedente es posible reconocer la relación entre identidad y contexto, desde la perspectiva de la evaluación permanente que hace la masculinidad hegemónica de los mandatos validados. Desde allí, la construcción del discurso de masculinidad, compartido socialmente, va tomar mayor relevancia en el proceso de identificación.

La formación discursiva de la masculinidad hegemónica implica todas aquellas prácticas pertenecientes al ámbito de la dominación y sumisión, es decir, a la demostración efectiva de subordinación de la construcción subalternizada de otre. En el plano del erotismo masculino, no existirían diferencias absolutas entre varones hetero y homosexuales desde el comportamiento sexual, sino que esta división estaría en el plano de lo mental y lo cultural. Pero esta reflexión deja fuera a la construcción diversa de las identidades, es decir, no contempla la posibilidad de comprender que existen diferentes maneras de vivir las masculinidades, no necesariamente desde el binarismo heterosexualhomosexual (Pecheny, Figari y Jones, 2008), por lo que las características de aquellas masculinidades contrahegemónicas presentan amplias maneras de reconocerse como tal. El punto central es que, a diferencia de lo heteronormado, las masculinidades contrahegemónicas permiten la manifestación explícita de posibilidades de establecimiento de relaciones desde contextos que visibilicen y cuestionen estos contextos de violencia, dominación y sumisión, característicos de los mandatos masculinos heteronormados hegemónicos. Por ello, es probable considerar que, dentro de los contextos de la sociabilidad homosexual, también se perpetúen espacios de subordinación y dominación propios de las estructuras hegemónicas. Con esto, comprendemos que la identificación con una sexualidad disidente no constituye una práctica contrahegemónica por sí misma. 
No puedo decir que lo he vivido, no ha sido una experiencia en plenitud, pero sí ha sido una experiencia grata, como homosexual me han tocado, no del todo, pero sí muy buenas amistades que la vida me ha puesto en el camino, y agradezco un montón. Ha sido una buena experiencia desde que decidí "salir del closet", conmigo mismo y después con mi familia, con parte de mi familia, la mayor parte, siento que ha sido un gran avance de tranquilidad para mi, sobre todo ha sido algo gratificante. Veo más ser homosexual como un don que una carga, o un problema... (E7, 26 años, Valparaíso)

Por ello, los aspectos identitarios vinculados con las experiencias pueden llegar a parecer espacios de apropiación y autonomía desde la libertad del sujeto, dada las posibilidades que entrega un contexto social particular de visibilizar las subjetividades abyectas, pero esto no impide la sanción social, mayor o menormente velada, a razón de la orientación sexual del sujeto. Es decir, la sexualidad se transforma en un factor de sanción y exclusión que, en la relación con ciertos contextos, puede estar más oculta o visible, pero siempre presente.

El devenir histórico de Chile, así como noventas a dos mil, es como un periodo tan restrictivo, tan normado, tan consensuado, así como plantea la concertación, y ese proyecto en los discursos entre los poderes, la normalización que se planteaba en términos políticos y en términos sexuales, o sea, todavía generaba conflicto el tema de la píldora o diferentes temas que podían ser catalogados como inmorales, y en este espacio de Santiago como que irrumpí todo esos legados que dejó la dictadura y la concertación que los acentuó, y que me hizo posicionarme desde un punto de vista súper crítico, o sea yo creo que la universidad me dio las herramientas para criticar, cuestionarme a mí mismo, cuestionar los pensamientos, como tú dices, anteriormente, como me pensaba, supuestamente tenía que ser como concordante mi sexo con mi manifestación de género... (E3, 22 años, Santiago)

En el contexto de la modernidad, las identidades se constituyen en dispositivos de poder, desde los que se controla el deseo y las sexualidades, por tanto, reflejan que los parámetros del control están en el ámbito de la normalidad y anormalidad. Estas relaciones son presentadas por Michel Foucault a través del concepto de "biopoder" (Foucault, Ewald, Fontana y Senellart, 2016), como estrategias de control 
del ser humano desde sus aspectos biológicos esenciales. Es decir, el poder se manifiesta en la planificación de la manipulación y control desde la normalización.

Como que siento que siempre, por ejemplo, como que... no sé por qué existe esta hueá de que -igual es un poco una realidad_, de que los fletos no juegan a la pelota, pero yo creo que no es que no quieran jugar a la pelota, yo quizás sí quería jugar a la pelota, el tema es que el grupo al cual yo quería acceder para poder jugar a la pelota, me rechazaba o no me escogía, entonces no que yo no quisiera jugar a la pelota, como que al final opté por "listo, no quiero... no es lo mío". Más fácil que estar exponiéndose, tener que demostrar que igual erí bueno corriendo, que igual podí ser bueno para la pelota, no sé... (E1, 24 años, Santiago)

El control de las subjetividades se hará mayormente visible, por tanto, en los aspectos normativos de la vida cotidiana de los sujetos, en los espacios de socialización y sociabilidad desde los cuales se construye el sujeto social, y en la interacción que profundiza los mandatos de la masculinidad hegemónica. Están presentes en las relaciones que establecemos con otros y en la manera que sancionamos la idoneidad del sujeto para ser merecedor de la categoría "hombre".

\section{Categoría mandato de masculinidad}

La categoría considera la evidencia presentada por los entrevistados, en el contexto de la permanente demanda por cumplir con aquellos patrones de dominación impuestos por esta masculinidad heteronormada, hegemónica y dominante. En palabras de Rita Segato, estos mandatos de masculinidad se vinculan con los contextos sociales desde los que están siendo descritos. Especialmente en América Latina, las condiciones de desigualdad e inequidad hacen que muchas características de esos mandatos sean inalcanzables por muchos hombres. Esta necesidad de "demostrarse hombre y no poder hacerlo por no tener los medios, [hace que] sean victimizados por ese mandato y por la situación de falta absoluta de poder y de autoridad a que los somete la golpiza económica que están sufriendo (Segato, 2019), generando aún mayor tensión en los contextos de desigualdad local. Es por ello que los mandatos de masculinidad deben comprenderse en la relación que establecen con el sujeto situado y cómo estos diferentes espacios van 
a profundizar las relaciones de dominación con aquellas masculinidades alternativas. Esto se refleja en el siguiente relato:

Ha sido un proceso eso de replantearse la masculinidad. Me pasa que, en algún momento de mi vida, el no poder encajar en el estándar de masculinidad me hacía daño, o me hacía, de cierta forma, sentir como fuera de lugar. Como que siempre, para poder accerder a un grupo de hombres, uno tiene que mostrar una masculinidad estereotipada, pero con el tiempo como que he ido logrando deconstruirlo y generando otro significado para lo que es la masculinidad. (E1, 24 años, Santiago)

Los mandatos de la masculinidad hegemónica estarán constantemente tensionando lo opuesto para reafirmar lo propio, es decir, generarán un proceso de reafirmación en la medida en que el sujeto identifique claramente lo que no es masculino. Estas definiciones de lo no masculino estarán en concordancia con los contextos sociales y culturales que le darán un marco, pero fundados también en la relación de lo repudiado con lo abyecto (Fuller, 2018). El repudio a lo que está fuera de la idea de "masculinidad" va a servir como límite para estos mandatos, ubicando rápidamente a quiénes merecen o no la nominación de "hombre". Estar fuera de ese esquema, es decir, al margen de lo masculino, permitirá la identificación de abyecto. Por tanto, "la masculinidad adquiere coherencia y estabilidad a través del repudio de lo abyecto. Este último produce sus fronteras y estabiliza la masculinidad, en una operación que permite a los hombres identificarse con su género" (p. 29).

Los relatos sobre las dimensiones del rechazo a lo abyecto permean las propias relaciones familiares:

La primera vez que estuve pololeando fue un poquito complejo, pero como yo no vivía con mi papá, fue diferente, yo sabía la aceptación que me iba a dar mi papá y la aceptación que me iba a dar mi mamá. Mi papá, por supuesto, todo el apoyo, todo perfecto, desde el sentido de conocer a tus parejas, desde el momento que me decía "yo te puedo comprar tus preservativos, quiero conocer tu mundo, todo." Mi mamá en ese momento no, se cerró: "no quiero saber nada, está bien, es tu vida, pero estudia, o sea, yo no quiero saber con quién andai, yo no quiero saber tus historias, no quiero conocer esa gente, 
nada", pero ella tuvo un cambio en ese pensamiento desde la muerte de Daniel Zamudio, ella tuvo un cambio muy significativo. Yo creo que me visibilizó en el chico, entonces ahí yo creo que sí, tuvo un cambio radical. (E6, 26 años, Santiago).

Se establecen patrones desde los cuales el rechazo, como estrategia de identificación de aquellas fronteras, se vincula con creencias, perjuicios, temores e inseguridades, planteadas desde la construcción colectiva de este ser anormal, en el contexto de la organización de la sociedad desde el control de los sujetos a través de las subjetividades, como se identifica en el relato siguiente:

Llegué a la universidad a los diecisiete, y a los veinte o veintiuno decidí contarle a mi mamá que era gay, lo cual fue una bomba en la casa, horrible, no se habló más del tema. Y dos años después le reafirmé que era gay. Ella pensó que me había "rehabilitado" por obra del Señor, y volvió a ser una segunda bomba, pero ya más relajado hasta el día de hoy, que sabe que soy gay y me acepta, y me ha aceptado con pareja en la casa, que es un cambio bastante drástico. Una pareja oficialmente presentada como pareja. Igual fue raro, porque se llevaba bien con mi mamá, no me esperaba una buena relación. (E7, 26 años, Valparaíso)

El mandato de masculinidad hegemónica, por tanto, opera en la medida en que identifica y sanciona las subjetividades que se alejan de este patrón. La necesidad de contar con un otro excluido y marginado va a ser una característica que compartirá con el modelo neoliberal imperante.

\section{Categoría contexto neoliberal}

La presente categoría emergente se presenta como resultado de las referencias que hacen los entrevistados en torno a la vinculación de sus propias biografías con el sistema imperante.

Desde las realidades constituidas por las masculinidades hegemónicas, las bases del control de los sujetos y la determinación de aquellos que quedan fuera de la categoría "hombre", ésta está fundada en los aspectos ideológicos que promueve el neoliberalismo, especialmente en las prácticas de género que promueven las relaciones de poder. Como indica Berenice Bento: 
A masculinidade hegemônica constrói uma ideologia que lhe dá sustentação, podendo ser caracterizada por um conjunto coerente de ideias que busca justificar, por meio de constuções cognoscíveis e discursivas as práticas dos homens. [...] define padrões de comportamento que devem ser seguidos pelos homens e se estrutura com base em relações assimétricas entre os gêneros. (2012, p. 90)

Estos discursos de segregación permiten la organización social mediante la identificación del sujeto abyecto, que da sentido y reafirma la idea validada desde el propio sistema exclusor. La construcción del sujeto en el contexto neoliberal imperante, por tanto, reconoce esta hegemonía como un modelo de relaciones único, capaz de organizar la sociedad y profundizar la subordinación de algunos colectivos por sobre otros. Desde aquí, las masculinidades contrahegemónicas reafirman su condición de marginales y vulnerables, en la medida en que cuestionan los patrones hegemónicos.

El siguiente relato puede ayudar a ilustrar esta relación de permanente segregación:

Todo esto que es el contexto, que es la cultura, que es como una hueá tan amplia y tan abstracta, se va encarnando en la persona, se va psicologizando en esa persona y, en el fondo, por eso es que los gays somos tan propensos [...], pero en el fondo las personas que tenemos una sexualidad no heteronormada o no hegemónica, somos tan propensos a la soledad, somos tan propensos a la depresión, al suicidio, porque en el fondo son todas estas prácticas de la cultu$\mathrm{ra}$, son todos estos elementos culturales [...] que han sido como tan instalados de forma tan fija, que generan hostilidad, que generan violencia, todas esas cosas en el fondo te terminan aislando como sujeto y a eso, no sé poh, le sumamos el factor gueto, que es el mundo fleto, cachai, el factor superficial que es el mundo fleto, el factor VIH, y cada vez más te vas como disolviendo y sintiendo cada vez más solo siento yo [...], no es necesario de una dictadura como fáctica cachai, como algo que existe, sino que en el fondo la dictadura sigue estando en nuestras vidas y no tan solo la dictadura, cachai, si igual en el fondo la dictadura es como cuando las clases poderosas se rasgan las vestiduras, cuando el poder de los que realmente nos dominan se hace más visible, eso es la dictadura al fin y al 
cabo, pero nosotros vivimos en una constante opresión, entonces esa opresión como que atraviesa nuestras vidas, cachai, y eso es lo que genera angustia, depresión, suicidio, que son hueás terribles. (E1, 24 años, Santiago)

Desde Lyotard, con la crítica que hace a la razón posmoderna sobre el fin de las utopías, podemos identificar la profundización de los contextos de dominación y control que, con la propuesta de Foucault, se desapegan de las razones del capital para organizarse en elementos transversales del sujeto, en la medida en que estos permiten la subordinación a un sistema de control, y la irrupción de Derrida, con la incorporación de la deconstrucción de las palabras y conceptos, el neoliberalismo ha ido construyendo un escenario de representación de ciertos contextos (Bernabé, 2018) desde la inequidad y desigualdad, como los feminismos y el movimiento que agrupa a Lesbianas, Gays, Bisexuales, Transexuales, Intersexuales y otres (LGBTI+), dentro de límites que los minimizan y opacan. Por ello, estos movimientos reivindicatorios van a tener un papel marcado y específico en el contexto neoliberal, mientras siguen siendo capturados por discusiones que no llevan a la emancipación de estos colectivos, sino que les entregan espacios de participación delimitados, siempre desde una posición subalterna. Esta desideologización es funcional al modelo neoliberal y ayuda a la masificación de la versión hegemónica de la masculinidad.

Una representación de ese contexto neoliberal se evidencia en el siguiente relato:

Siento como una amputación del tejido social, cachai, como un modelo capitalista súper heavy, que transforma a la sociedad chilena en una sociedad super reprimida, muy misógina y doble estándar, cachai [...], la dictadura que cambia, destruye y construye desde cero son muchos elementos; construye primero un proyecto político, moral superior, potente, y otro elemento quizás igual de importante, el tema económico, o sea, primero un proyecto moral, como decías tú bastante bien, un proyecto de país desde una visión única, que es principalmente católica, como sabemos todos, desde la perspectiva de la familia, como núcleo de la sociedad, etcétera. Todas esas cuestiones que dice la misma Constitución, hecha por este mismo señor y otro modelo de sociedad también, donde 
el liberalismo económico es como parte de las libertades personales [...] que afectan a la construcción de la persona. (E2, 23 años, Santiago)

Por tanto, los movimientos de visibilización de las desigualdades, especialmente vinculados a la diversidad sexual, verán constantemente frustradas sus expectativas por convertirse en partícipes activos de las decisiones locales, en la medida en que son considerados de segundo orden y subalternizados a través de la atomización y la apropiación de sus demandas en pro de la dignidad y reconocimiento. Esta situación sitúa a las masculinidades no hegemónicas en una situación de tensión e incertidumbre, en un contexto en el que la visibilización de las diferencias se hace desde los contextos permitidos por el sistema, es decir, desde aquellos espacios que no ponen en peligro la continuidad del programa ideológico neoliberal.

\section{Reflexiones finales}

Este espacio, a modo de corolario, busca organizar las reflexiones que surgen del análisis de los discursos de los sujetos convocados, junto con tensionar, desde las propuestas teóricas precedentes, las oportunidades que entrega la intervención social en el campo de las masculinidades contrahegemónicas en el contexto neoliberal actual. Desde esta propuesta, surge como elemento base la caracterización del sistema político, social, económico y cultural que nos domina, como un "modelo que generó una sociedad con una marcada desigualdad en diversos ámbitos y un predominio económico financiarista. Terminó por empobrecer a amplios sectores, además de deteriorar el empleo, e intensificó la vulnerabilidad de la economía frente al exterior" (Gutiérrez, 2019, p. 267). Este presupuesto básico nos permite construir una serie de relaciones que vinculan este contexto hegemónico con la relación subalterna con las subjetividades. Por ello, considero fundamental proponer algunas ideas que orienten la potencial intervención social con los contextos de desigualdad y dominación de las masculinidades no hegemónicas evidenciadas como consecuencia de la implementación de este modelo.

En primer lugar, la relación entre mercado y subjetividades subalternas, en el contexto neoliberal, propicia el entendimiento de aquel sujeto contrahegemónico desde los espacios que promueve el neo- 
liberalismo, es decir, desde una relación de producción y consumo. Esta situación cosifica y despolitiza al sujeto, le otorga una calidad distinta a la de ciudadano y le obliga a establer un vínculo con la sociedad desde los presupuestos del capital sexual tardomoderno (Illouz y Kaplan, 2020), es decir, desde la concepción de las diferencias sexuales como parte integrante de una relación mercantil, trasladando el valor de la persona y el ciudadano a categorías mercantiles. Reconocer esta relación, dentro de las fronteras del neoliberalismo, permite su caracterización profunda, junto con el análisis de las posibilidades de transformación y valoración del sujeto en tanto ciudadano, y la oportunidad de ofrecerle caminos de tránsito hacia la resignificación como sujeto, más allá del mercado. Esta significación, desde el capital social tardomoderno, no establece un vínculo solamente a través de su condición de género binario (hombre, mujer), sino que impone una condición de clase que lo posiciona en una escala de estratificación social. Es esta característica la que me parece relevante al momento de pensar estrategias de intervención social complejas, que permitan promover una transformación en esta valoración del sujeto masculino subalterno.

Como segundo punto, vinculado a la propuesta anterior, está la necesaria vinculación con la formación profesional y los contenidos y valores requeridos para la comprensión cabal de los contextos promovidos por el neoliberalismo, junto con un análisis crítico contextual y la generación de profesionales que reconozcan el valor de las reivindicaciones de género que han permitido visibilizar las desigualdades en el contexto neoliberal. Desde allí, me parece relevante la reflexión que hace Victoria Gálvez (2016) contra la estigmatización de las demandas feministas en los espacios universitarios. Como indica:

Los segmentos excluidos de una sociedad no necesariamente tienen consciencia de ello, su identificación con el poder, les anima una cierta sospecha hacia el feminismo, del mismo modo fomenta la falta de interés a que las instituciones educativas incluyan los estudios de género como parte de sus actividades curriculares. La desigualdad, la inequidad y la indiferencia frente a esto, es materia de derechos humanos. La academia por tanto debiera ser la más proclive a garantizarlos en su praxis, como una tarea de suyo que corresponde en tanto referentes ético-jurídicos, ya que han sido el 
basamento de las cartas orientadoras para la vida social y política de los pueblos. Los escasos debates sobre los derechos humanos en la formación, implican que texto y contexto tiendan a asemejarse en relación a la participación, a la toma de decisiones o a la inclusión de la diversidad, con la mantención de dicotomías históricas. (p. 91)

Esta responsabilidad social de la academia se va diluyendo en el mismo contexto neoliberal desde donde se producen los cuestionamientos a los movimientos reivindicativos de género, a la lucha de las mujeres por el reconocimiento de su situación de víctimas de un sistema patriarcal exclusor, junto con la denuncia de las condiciones de dominación y desprestigio que sufren las diversidades sexuales.

En tercer lugar, se hace urgente la transformación de los dispositivos de intervención social promovidos desde el Estado, en concordancia con el cuestionamiento del sujeto de intervención despolitizado y carente, propio de los procesos interventivos propiciados desde el capitalismo. Es por ello "comprender la intervención social como una interferencia intencionada para cambiar una situación social que, desde algún tipo de criterio, se juzga insoportable, por lo que precisa de cambio o corrección en una dirección determinada (Sánchez Vidal, 1999, p. 74), potenciaría la urgencia de establecer acciones concretas de empoderamiento y promoción de una ciudadanía deliberativa. La subyugación política, al generar espacios de nominación de los contextos de diversidades sexuales desde la idea de minoría, propicia el reconocimiento de los sujetos desde la perspectiva de una ciudadanía de segunda clase, tutorizada y valorada solo desde la carencia: en este caso, la exclusión social.

Esta relación de sometimiento promueve la organización de estrategias de intervención social desde la organización burocrática de los dispositivos interventivos, haciendo aún más compleja y difícil la relación de empoderamiento de los sujetos, en su calidad de ciudadanos.

La burocratización de la intervención estratifica, segmenta y minimiza a los sujetos, los convierte en receptores pasivos de productos pensados para administrar la carencia y, por tanto, sobrellevar la condición de vulnerabilidad. Es decir, desempodera al sujeto, lo pri- 
va del ejercicio de su ciudadanía y lo ubica como un sujeto subalterno, en un contexto en el que la administración de los contextos que le aquejan va a estar desorganizada en diversas reparticiones que no dialogan ni interactúan. Por tanto, este proceso de operacionalización de las necesidades, deshumaniza y transforma cualquier intento de inclusión, en una tarea administrativa de gestión de recursos (Ruiz Ballesteros, 2005).

Reconocer estas condiciones propiciadas por el sistema neoliberal imperante promueve un proceso contrahegemónico del más alto valor, que permitiría restituir la calidad de personas a los sujetos que se encuentran en calidad de subalternos y marginados en razón de su orientación sexual, es decir, como producto de identificarse desde subjetividades abyectas que les han relegado y desplazado como personas, en el contexto actual.

\section{Bibliografía}

Azócar, R. (2015). Diversidad Sexual e Intervención Social: Reflexiones desde el Trabajo Social. Revista Perspectivas, 26. DOI: https://doi.org/10.29344/07171714.26.430

Barrientos, J. y Espinoza, R. (2019). Sexualidad y relaciones de género: Un campo de ciudadanía en transformación, en C. Berríos y C. García (Eds.), Ciudadanías en Conflicto: Enfoques, experiencias y propuestas. Nueva edición [en línea] (pp. 293-312). Santiago: Ariadna Ediciones. Recuperado de http://books. openedition.org/ariadnaediciones/1235

Becker, H. S. (2009). Outsiders: Estudos de sociologia do desvio. Rio de Janeiro: J. Zahar.

Bento, B. (2012). Homem não tece a dor: Queixas e perplexidades masculinas. Natal: EDUFRN.

Bernabé, D. (2018). La trampa de la diversidad: Cómo el neoliberalismo fragmentó la identidad de la clase trabajadora. Tres Cantos: Akal.

Bonino, L. (2002). Masculinidad hegemónica e identidad masculina. Dossiers feministes, 6, 7-35.

Careaga Pérez, G. y Cruz, S. (2006). Debates sobre masculinidades: Poder, desarrollo, políticas públicas y ciudadanía. México: UNAM, Programa Universitario de Estudios de Género. 
Carrillo, J. (2010). El neoliberalismo en Chile: Entre la legalidad y la legitimidad. Entrevista a Tomás Moulián. Perfiles latinoamericanos, pp. 145-155.

Connell, R. (2006). Desarrollo, globalización y masculinidades. En G. Careaga y S. Cruz, Debate sobre masculinidades. Poder, desarrollo, políticas públicas y ciudadanía. Ciudad de México: Universidad Nacional Autónoma de México.

Connell, Raewyn, Artigas, I y Vericat, I. (2015). Masculinidades.

De Miguel, A. (2015). Neoliberalismo sexual. Madrid: Difusora Larousse-Ediciones Cátedra.

Duarte, K. y Farías, F. (2019). Hacerse varón y adulto en liceos empobrecidos. La promesa de género y generación para jóvenes chilenos, en E. Martínez, A. Téllez y J. Sanfélix (Eds.), Deconstruyendo la masculinidad. Cultura, género e identidad. Valencia: Tirant Humanidades.

Foucault, M., Ewald, F., Fontana, A. y Senellart, M. (2016). Nacimiento de la biopolítica: Curso del Collège de France, (1978-1979). Madrid: Akal.

Fuller, N. (Ed.). (2018). Dificil ser hombre: Nuevas masculinidades latinoamericanas (Primera edición). Lima, Perú: Fondo Editorial, Pontifícia Universidad Católica del Perú.

Gálvez, V. (2016). La ausencia de memoria histórica sobre el feminismo en la academia chilena: Un debate sobre derechos Humanos. Fémeris: Revista Multidisciplinar de Estudios de Género, 1, 74-94. DOI: http://dx.doi.org/10.20318/femeris.2016.3228

Guevara, E. (2008). La masculinidad desde una perspectiva sociológica. Una dimensión del orden de género. Sociológica, 23(66), 71-92.

Gutiérrez, L. (2019). Neoliberalismo y Modernización del Estado en Chile: Emergencia del Gobierno Electrónico y desigualdad social. Cultura-Hombre-Sociedad, 29(2), 259-280.

Hernández, R. y Mendoza, C. P. (2018). Metodología de la investigación. Las rutas cuantitativa, cualitativa y mixta. Ciudad de México: McGraw-Hill Education.

Iglesias, M. (2015). Lo social y lo político en Chile: Itinerario de un desencuentro teórico y práctico. Izquierdas, 22, 227-250.

Illouz, E. y Kaplan, D. (2020). El capital sexual en la modernidad tardía. Barcelona: Herder. 
Marqués, J. V. (1997). Varón y patriarcado, en T. Valdés y J. Olavarría (Eds.), Masculinidad/es. Poder y crisis (pp. 17-30). Santiago de Chile: Isis Internacional.

Martín, S. \& De Lima, G. (2020). Identidades e sexualidades hegemônicas e contra-hegemônicas. Feminidades e masculinidades em tempos autoritários. Locus, revista de história, 26(1). DOI: https://doi.org/10.34019/2594-8296.2020.v26.30317

Martínez, S., y Agüero, J. (2018). Trabajo Social emancipador. Paraná: Fundación La Hendija.

Muñoz, H. (2017). Hacerse hombres: La construcción de las masculinidades desde las subjetividades. Medellín: Universidad de Antioquia.

Palet, A., De Aguirre, P. y PNUD Chile (Eds.). (2017). Desiguales: Orígenes, cambios y desafios de la brecha social en Chile. Santiago, Chile: PNUD, Uqbar Editores.

Pardo Abril, N. G. (2007). Cómo hacer análisis crítico del discurso: Una perspectiva latinoamericana. Santiago de Chile: Frasis.

Pecheny, M., Figari, C. y Jones, D. (Eds.). (2008). Todo sexo es político: Estudios sobre sexualidades en Argentina. Buenos Aires: Libros del Zorzal.

Pelucio, L. (2011). Marcadores Sociais da Diferença nas Experiências Travestis de Enfrentamento à aids1. Saúde e Sociedade, 76-85.

Rodríguez, J. (2019). ¿Qué es lo auténticamente neoliberal y qué es transversal? Gestión y Tendencias, 12-15.

Ruiz Ballesteros, E. (2005). Intervención social: Cultura, discursos y poder: aportaciones desde la antropología. Madrid: Talasa.

Ruiz Olabuénaga, J. I. (2012). Metodología de la investigación cualitativa. Bilbao: Universidad de Deusto.

Sánchez Vidal, A. (1999). Ética de la intervención social. Barcelona: Paidós.

Segato, R. (2010). Las estructuras elementales de la violencia. Ensayos sobre género entre la antropología, el psicoanálisis y los derechos humanos. Buenos Aires: Prometeo Libros.

Segato, R. (2016). La guerra contra las mujeres. Madrid: Traficantes de sueños.

Segato, R. (2019, septiembre 1). ¿Por qué la masculinidad se transforma en violencia? [Diario Digital Femenino]. Recuperado de https://diariofemenino.com.ar/rita-segato-por-que-la- 
masculinidad-se-transforma-en-violencia/\#: :text=Lo\%20 que\%20llamo\%20mandato\%20de,por\%20no\%20tener\%20 los\%20medios.

Yuni, J. A. y Urbano, C. A. (2014). Técnicas para investigar. Volumen 2. Recuperado de http://0-site.ebrary.com.fama.us.es/lib/unisev/Doc?id=10995327 